Preprints of the

Max Planck Institute for

Research on Collective Goods

Bonn 2012/1

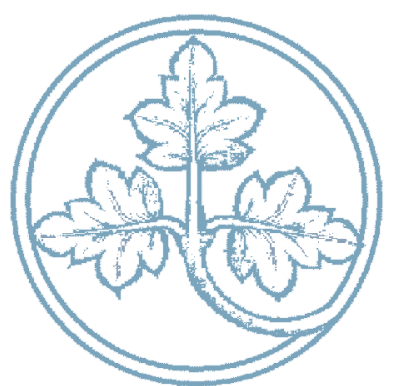

Symmetric vs. Asymmetric Punishment Regimes for Bribery

Christoph Engel Sebastian J. Goerg Gaoneng Yu

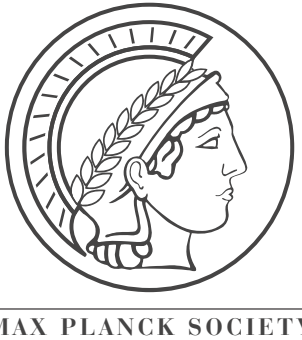




\title{
Symmetric vs. Asymmetric Punishment Regimes for Bribery
}

\author{
Christoph Engel / Sebastian J. Goerg / Gaoneng Yu
}

January 2012,

revised May 2013 


\title{
Symmetric vs. Asymmetric Punishment Regimes for Bribery*
}

\author{
Christoph Engel $^{\mathrm{a}}$, Sebastian J. Goerg ${ }^{\mathrm{b}, \mathrm{a}}$ and Gaoneng $\mathrm{Yu}^{\mathrm{c}, \mathrm{a}}$
}

May 31, 2013

\begin{abstract}
In major legal orders such as the UK, the U.S., Germany, and France, bribers and recipients face equally severe criminal sanctions. In contrast, countries like China, Russia, and Japan treat the briber more mildly. In this paper, we investigate which strategy is more effective in curbing corruption: symmetric or asymmetric punishment? To answer this, we manipulate the symmetry of punishment in a lab experiment. To control for unobserved cultural factors, we run the identical experiment in Bonn (Germany) and Shanghai (China). Our results suggest that, independent of culture and legal origin, asymmetric punishment gives bribers a behaviorally credible technology for enforcing corrupt deals.
\end{abstract}

Keywords: Bribery, Punishment, Effectiveness, Asymmetry, Legislation JEL: C91, D02, D03, D73, K14, K42

${ }^{*}$ We would like to thank the teams of the BonnEconLab, University of Bonn, and of the Vernon-Smith Experimental Economics Research Center, Shanghai Jiao Tong University for supporting the conduction of the experiments. We thank Sophie Bade, Hanjo Hamann, Xiangdong Qin, Lawrence M. Solan, and the audiences at the 6th Conference on Empirical Legal Studies and the MPI seminar for valuable comments and discussions. Financial support by the Max Planck Society is gratefully acknowledged.

${ }^{a}$ Max Planck Insititute for Research on Collective Goods, Bonn, Germany.

${ }^{b}$ Department of Economics, Florida State University, Tallahasse, USA.

${ }^{c}$ School of Law, Northwest University, Xi' an, China. 


\section{Introduction}

Corruption is among the most vexing social evils. ${ }^{1}$ Corruption is not only a blatant violation of good governance and procedural fairness; it also stifles economic growth (Mauro, 1995; Knack and Keefer, 1995). At least in the books, all legal orders of the world are therefore united in criminalizing corruption. Yet different legal orders adopt different regulatory strategies. One important difference has attracted little academic interest: while some countries target bribers and recipients symmetrically, others threaten recipients with much harsher punishment.

In major Western countries like the U.S. ${ }^{2}$, the $\mathrm{UK}^{3}$, and France ${ }^{4}$, bribers and recipients usually expect equally severe sanctions. In other legal orders punishment is asymmetric, in the sense that the prescribed punishment for the payer is mild relative to that for the receiver. This is the case in China ${ }^{5}$, Japan ${ }^{6}$, and Russia ${ }^{7}$. Germany has a mixed system. It has symmetric punishment for discharge-of-duty bribery ${ }^{8}$ and asymmetric punishment for violation-of-duty bribery. ${ }^{9}$. At closer sight, the US solution is also not completely symmetric. The 2010 Federal Sentencing Guidelines Manual distinguishes between officials and non-officials when allocating the base level punishment to bribery. ${ }^{10}$ Refer to Appendix B for a more detailed account of the different legal provisions.

In this paper, we bracket broader issues of justice and focus on a question that is preliminary to any normative discussion of the difference: which solution is more effective in reducing collusive bribes? Specifically, we ask the following four questions: do symmetric and asymmetric punishment have different effects on potential offender decisions: (1) Whether to make an offer? (2) Whether to accept the offer? (3) Whether to do a favor after accepting an offer? (4) Whether to self-report after an offer is accepted but no favor returned?

Testing these questions in the field would have been hard, if not impossible. Payers and receivers have a strong incentive to keep corruption confidential. Even if policy makers were willing

\footnotetext{
${ }^{1}$ See the Corruption Perception Index of Transparency International for the empirics, available via http://www . transparency.org/policy_research/surveys_indices/cpi

${ }^{2}$ See the U.S. Code $18, \S 201(\mathrm{~b})$

${ }^{3}$ See the Public Bodies Corrupt Practices Act 1889 s2 and the Prevention of Corruption Act 1906 s1.

${ }^{4}$ See the French Penal Code, Articles 432-11, 433-1, 433-2, 434-9.

${ }^{5}$ See the Criminal Law of the People's Republic of China, Article 383, 386, 390.

${ }^{6}$ See the Penal Code of Japan, Article 197 through 197-4, 198.

${ }^{7}$ See the Criminal Code of the Russian Federation Article 290.

${ }^{8}$ See the German Penal Code (Bohlander, 2008) $§ 331, \S 333$.

${ }^{9}$ See the German Penal Code (Bohlander, 2008) $§ 332, \S 334$.

${ }^{10}$ The base level punishment is 14 if the defendant was a public official and 12 otherwise $(\S 2 \mathrm{C} 1.1$. (a)). Note, however, that in United States v. Booker, 543 U.S. 220 (2005), the Supreme Court decided that the guidelines violate the Sixth Amendment right to trial by jury. Since then, the guidelines have been considered advisory only, at both the federal and the state levels. Sentences above the range of the guidelines are imposed at a rate double that of the rate before Booker. See Doerr (2009).
} 
to experiment with the symmetry versus asymmetry of punishment, the resulting degree of corruption, i.e., the dependent variable, could not be measured reliably. An experiment in the lab offers a viable solution. In a set of experiments on collusive bribery, we manipulate punishment strategies to observe their effects on the bribery decision-making. Given that the different punishment regimes discussed above are effective in societies with different cultural backgrounds, one might argue that culture determines the most efficient regime. To ensure the robustness of our results across countries the experiments are conducted in Germany and China, two countries with different cultural backgrounds and legal orders.

With asymmetric punishment, bribers are much more likely to report to the authorities if the official accepts the bribe but does not grant the favor. This is rightly anticipated by officials. They are slightly less likely to accept the bribe, but if they do, they are much more likely to grant the favor. Punishment sentiments give bribers a behaviorally credible threat. In the shadow of this threat, corrupt deals are almost perfectly enforced. This holds both in Germany and in China and suggests that our results are not driven by cultural or legal differences.

The remainder of the paper is organized as follows: Section 2 reviews the related work. Section 3 presents the design of the experiment and makes theoretical prediction. Section 4 is the results section. Section 5 concludes with a discussion and policy implications.

\section{Related Work}

Over the last ten years the empirical literature on corruption has tremendously grown; an overview of the insights obtained with experiments is provided in Serra and Wantchekon (2012), and resulting anti-corruption policies are discussed by Abbink and Serra (2012).

The most prominent prerequisites for successful bribes are trust into the confederate and a reciprocal relationship between briber and receiver. Because of these two influences bribes occur even if they are in sharp contrast to equilibrium behavior (Abbink et al., 2002) and can be enforced by the threat of punishing those who do not return a favor through (costly) self-reporting (Lambsdorff and Frank, 2011). Rose-Ackerman (1999) argues theoretically that asymmetric penalties might undermine exactly this trusting relationship between briber and receiver. Along this line, Lambsdorff and Nell (2007) reason that double-dealing, whistle-blowing, and extortion might cause significant uncertainties for participants of corrupt transactions. Thus, legislators might use an asymmetric design of criminal sanctions ${ }^{11}$ and leniency programs to amplify these inher-

\footnotetext{
${ }^{11}$ Lambsdorff and Nell (2007) show that the recipient of a bribe should be punished less for taking the money and more for reciprocating the bribe. Thus, by "asymmetric" the authors actually mean asymmetric definition of the
} 
ent risks and increase the transaction cost in corrupt deals, destabilize corrupt arrangements and disband the "pact of silence", thereby making participation less likely in one-shot interactions.

Similarly, Kingston (2007) introduces government as a strategic player that attempts to structure the game such that the level of corruption is reduced and shows that governments wishing to deter parochial corruption ${ }^{12}$ will usually prefer to punish only the official receiving the bribe, not the bribe-payer. This result is derived from the following reasoning:

Government can reduce the potential gains to the bribe-transacting parties by increasing the expected punishment of either party. However, increasing the official's punishment has an important additional benefit: it makes it harder for the parties to enforce the bribe transaction.

The same is not true for punishment of the bribe-payer.

Empirical evidence on the effectiveness of asymmetric punishment for bribery is provided by Schikora (2011), who demonstrates that giving leniency to a whistle blowing official weakens the stability of corrupt transactions. Yet, an asymmetry in punishment that favors the public official and not the payer is in sharp contrast to the prevailing application in criminal law and therefore to the mechanism tested in our experiment.

Although we focus on collusive bribes, our paper is related to the current discussion on harassment bribes proposing to punish only public officials while granting immunity to the bribe-giver (Basu, 2011). ${ }^{13}$ In the case of collusive bribes, officials and briber exchange favors for their mutual benefit, while in harassment bribes officials request bribes before delivering services they are supposed to provide, thereby abusing their power over the citizens. Abbink et al. (2012) investigate Basu's proposal for extortionary bribes with a model, lab experiments and surveys in India. They observe that asymmetric punishment of officials can decrease the officials' demand for bribes, but harassment bribes are not necessarily reduced as long as officials have means to retaliate against reporting citizens.

Related to these findings of the bribery literature are papers on leniency in anti-trust settings. ${ }^{14}$ The U.S. Department of Justice believes that "the early identification of antitrust offenses through compliance programs, together with the opportunity to pay zero dollars in fines under the Division's Corporate Amnesty program, has resulted in a 'race to the courthouse,'..." (Spratling, 1999).

elements of bribery offense, not asymmetric prescribed punishment, which is the topic of this paper.

${ }^{12}$ Parochial corruption refers to "a situation where only ties of kinship, affection, caste, and so forth determine access to the favors of power-holders" (Scott, 1972, p. 88).

${ }^{13}$ See Dufwenberg and Spagnolo (2011) for a theoretical discussion of the proposal by Basu (2011).

${ }^{14}$ Please note that bribery and cartels differ in several respects. Members of a cartel are basically in the same position and incur equal cost; in bribery cases the receiver usually has nearly no cost, whereas the payer bears at least the cost of the bribe. Cartels usually have more than two participants who act simultaneously, while bribery usually only involves two parties acting sequentially. Bribery can be one-shot, which is seldom the case for a cartel 
Spagnolo (2005) demonstrates in a theoretical model that this deterrence effect is even stronger if leniency does not only reduce sanctions, but in addition rewards spontaneous reports. In a market game experiment, Apesteguia et al. (2007) concluded that leniency policy yields significantly lower market prices and that there is some tendency towards fewer cartels and more cartel reports. However, moderate forms of leniency, i.e., without rewards, may have a counterproductive side effect. They "[...] could be exploited by sophisticated wrongdoers to implement occasional illegal transactions that would not be feasible otherwise." (Buccirossi and Spagnolo, 2006). Although the above stream of literature is related to our study, it should be noted that asymmetric punishment and leniency are not the same: asymmetric punishment is prescribed, definite, and unconditional, while leniency is ex post, at judicial discretion, and conditional on self-reporting.

Our study experimentally tests the effectiveness of different punishment regimes in two locations in China and Germany. Thus, our studies nicely ties up to papers investigating the impact of nations' characteristics and culture on corruption (Serra, 2006; Lambsdorf, 2006; Cameron et al., 2009; Barr and Serra, 2010; Geng and Hennig-Schmidt, 2011; Banuri and Eckel, 2012). Having said that, we are not focussing on the influence of culture, but use the differences (i.e., historical, legal, and cultural) between the locations as a robustness check for our results.

\section{The Experiment}

Bribery has rich features and occurs in various types. It is neither practical nor desirable to catch all of them in one simple experimental setup. The key advantage of a laboratory experiment is the isolation of a causal relationship. Therefore, our experiment is solely designed to test the effectiveness of symmetric and asymmetric punishment in preventing bribery. To do so, we adapt the design that is standard in the experimental literature on bribery.

\subsection{A Simple Bribery Game}

Assume the following situation: an individual has to decide whether to attempt a bribe or not. If he decides not to bribe, he faces no consequences, neither negative nor positive. But if he decides to approach a potential receiver, his fate depends on the decision by the receiver. The receiver can either reject the offer, accept it and provide a favor, or just accept the money without providing a favor. If the receiver rejects the offer, no additional consequences occur.

If the receiver accepts the bribe, a money transfer between the individual and the receiver takes place. The receiver has now two possibilities: he can either grant a favor which would result in a 
monetary be

risk of bein

to report the d implicate the

bing individual

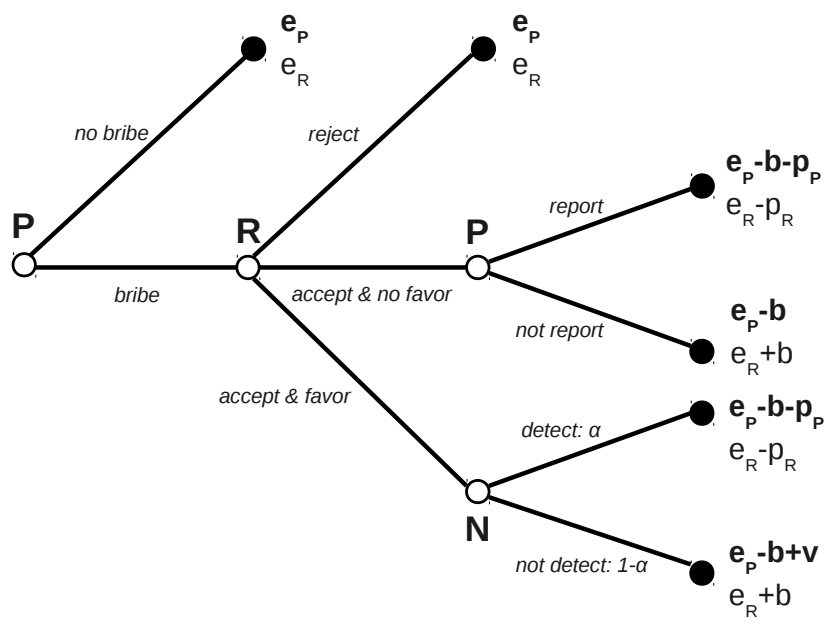

Figure 1: Bribery model

Figure 1 captures this situation. The two players, Payer $(P)$ and Receiver $(R)$, receive an initial endowment of $\mathrm{e}_{P}$ or $\mathrm{e}_{R}$, respectively. Both players keep their initial endowments if either $P$ decides not to bribe $R$ or if $R$ decides to decline $P$ 's offer. If the receiver decides to accept the bribe, the payoffs of the two players depend on the decision to grant a favor or not.

If $R$ grants a favor, Nature $(\mathrm{N})$ determines with a random draw whether the bribery is detected or not. With probability $\alpha$ the bribery is detected and with the probability $1-\alpha$ the bribery is not detected. If the bribery is detected, $P$ and $R$ receive a punishment of $p_{P}$ and $p_{R}$, respectively, and the bribe is confiscated. If the bribery is not detected, $R$ receives from player $P$ the transfer $b$, and for player $P$ the favor results in a monetary benefit of $v$.

If $R$ grants no favor, payer $P$ loses the transferred bribe $b$ without receiving a benefit. Thus, $P$ can either accept this situation or report the bribe to the authorities. Reporting to the authorities would result in punishment for both players, $R$ would receive a punishment of $p_{R}$ and $P$ one of $p_{P}$. In addition, the bribe $b$ is confiscated. If $P$ does not report to the authorities, $R$ keeps $P$ 's transferred bribe $b$ and $P$ would have to bear the costs without receiving a benefit.

This game allows us to vary the punishment regimes (i.e., the parameters of $p_{R}$ and $p_{P}$ ), while keeping everything else constant. The parameters for the experiments were set as follows: the endowment for the proposer $e_{P}$ and the receiver $e_{R}$ is 100 taler and 60 taler, respectively; the amount of bribe $b$ is 40 taler, if any; the gain for the proposer $v$ is 120 taler, which is three times the bribe; and the probability $\alpha$ of being detected is set to 0.25 . If an asymmetric punishment regime 


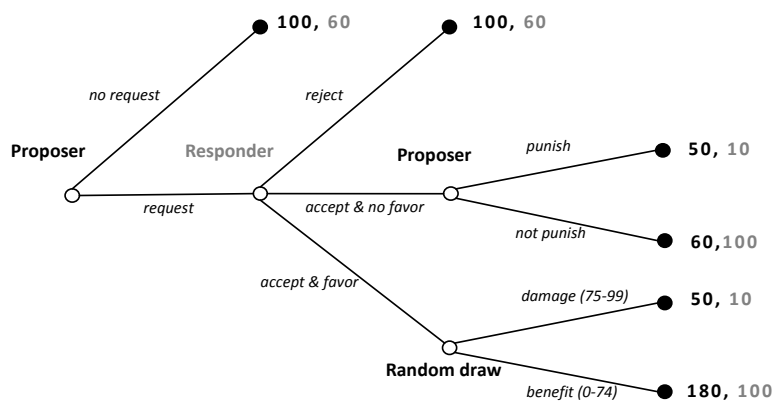

(a) Asymmetric punishment

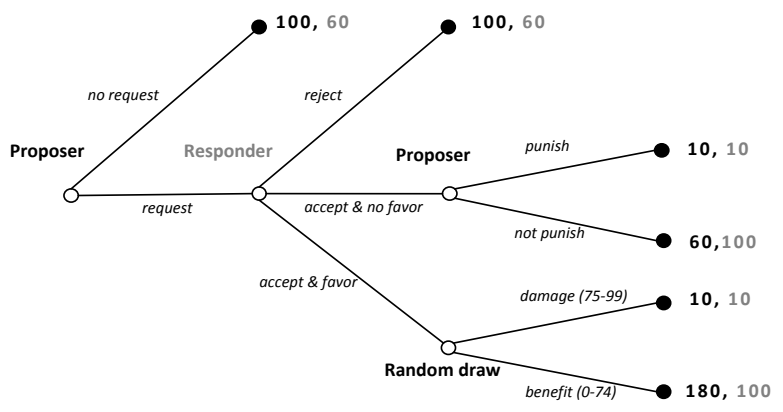

(b) Symmetric punishment

Figure 2: Game tree by punishment regime

is applied, punishment for the proposer $p_{P}$ is set to 10 taler, and for the receiver $p_{R}$ to 50 taler. In case of symmetric punishment, both player receive a punishment of 50 taler $\left(p_{P}=p_{R}\right)$. Figure 2 gives the game trees of both punishment regimes. It shows the actual payoffs in the experimental currency talers and the actual wording used in the experiments.

We chose the parameters to capture the key features of bribery and well-established legal doctrines. Thus our parameters fulfil the following conditions:

$$
\begin{aligned}
e_{P} & \geq b>0 \\
v & >b \\
p_{P}+b & >v-b \\
p_{R} & >b \\
(1-\alpha)(v-b) & >\alpha\left(p_{P}+b\right) \\
(1-\alpha) b & >\alpha p_{R}
\end{aligned}
$$

Inequality (1) is the briber's budget constraint. This condition also ensures that there are situations in which bribery pays for the client. Inequality (2) makes sure that the gain from bribery is larger than the bribe paid; otherwise there would be no incentive to bribe. Inequalities (3) and (4) are Bentham's Rule for the payer and the receiver respectively. Betham's Rule commands that the evil of the punishment must be made to exceed the advantage of the offence (Bentham, 1802). Inequalities (5) and (6) are the participation constraints for the payer and the receiver respectively. According to (Becker, 1968) a crime is only committed if the expected utility from committing the crime is higher than the expected utility of not committing the crime. Thus, the inequalities explain 
why there is still an incentive to bribe even if the evil of the punishment exceeds the advantage of the offence.

Before we turn to the experimental procedure and the behavioral predictions, we briefly discuss the underlying assumptions and simplifications of the game as described above:

- The game describes a situation in which bribery occurs at the sole initiative of the briber. The receiver is paid for the violation of his official duty, but we exclude situations in which the receiver asks for a bribe or even extorts it. The amount of the bribe is fixed and bargaining between payers and receivers is excluded. Once the bribe has been paid and accepted, the parties cannot voluntarily end their illegal relationship. If the briber reports, punishment of both parties is automatic. We thus abstract from later interaction with the authority. We remove this source of uncertainty in the interest of identifying the effect of punishment asymmetry.

- In this experiment, we ignore negative externalities on outsiders in case of successful bribery. We also refrain from framing the situation in a way that makes granting the favor immoral. We do so for the following reasons: First, bribery is an intentional crime and offenders might not care about induced externalities. ${ }^{15}$ Second, bribery is often erroneously believed to be a victimless crime and offenders might be unaware of externalities or at least unable to state the exact cost. Third, while awareness campaigns stating the exact costs of bribery for society are one possibility of public intervention, we would like to focus this paper on legal interventions. ${ }^{16}$

- The payer will not be sanctioned if the offer is rejected. This captures a situation where the payer has been cautious enough to approach the potential receiver in a way that cannot be proven in court.

- The main goal of this paper is to investigate the effect of different punishment regimes on fostering or deterring bribery. Therefore, we ignore the case of self-reporting to the authorities by the payer if a favor was granted (which might, for instance, result from moral compunctions).

\footnotetext{
${ }^{15}$ The 2008 milk scandal in China is a typical example. A spokesman said that the scale of the problem proved that it was "clearly not an isolated accident, [but] a large-scale intentional activity to deceive consumers for simple, basic, short-term profits."

${ }^{16}$ It should be noted that experiments have produced contrasting results on the effect of externalities on bribery rates, e.g., Abbink et al. (2002) and Barr and Serra (2007). We are aware that introducing and stating the exact size of negative externalities can lead to moral compunctions and reduce observed incidents of bribes, but we assume that there is no interaction with the type of punishment.
} 
- There is no external detection if the offer has been accepted but no favor granted. We do so in the interest of isolating effects. With our design, if the recipient takes the bribe, but does not grant the favour, the only risk is revenge.

- The detection probability is $25 \%$. Arguably, at least for some types of bribery, this probability is considerably lower. Then asymmetric punishment may seem more attractive as a way for the authorities to learn about the offense. Yet leniency, i.e. a privilege conditional on the authority not knowing and being able to convict the official, would be better targeted. And the less detection is likely, the bigger the social damage if asymmetry makes it easier to enforce corrupt deals, as we hypothesize.

Despite these assumptions and simplifications our game captures the essence of collusive bribery: successful bribery results in a reciprocal relationship between payer and receiver, which is advantageous for both parties. This relationship is threatened with detection, resulting in severe (monetary) sanctions. Exactly this situation is described by the game above.

\subsection{Experimental Procedure}

For this study, experiments in Germany and in the PR China were conducted. Choosing two different locations is meant as a robustness check. We want to see whether the results reflect a generalizable effect, rather than differences in national cultures, or in the legal environment. ${ }^{17}$ In Germany, the experiments were run at the BonnEconLab of the University of Bonn and in China at the Vernon-Smith Experimental Economics Research Center of the Shanghai Jiao Tong University. ${ }^{18}$

In the experiment, two different punishment regimes were tested: asymmetric punishment and symmetric punishment. In each city, two sessions per punishment regime were conducted, with 24 subjects per session. Subjects were randomly assigned either to the role of a proposer or to the role of a responder and groups of two (one proposer and one responder) were randomly matched. In total we have 192 participants, who were mainly undergraduate students from various disciplines, including law, economics, political science, and mathematics (Germany: 50\% female, age $M=$ 23; China: $41 \%$ female, age $M=21$ ). Table 1 summarizes the treatments and the number of independent observations.

\footnotetext{
${ }^{17}$ Those readers who have a specific interest in the influence of culture on corruption may want to refer to the paper by Barr and Serra (2010) and those interested in the sensitivity to bribery in China to Geng and Hennig-Schmidt (2011).

${ }^{18}$ The experimental software was programmed in z-Tree (Fischbacher, 2007). Refer to the appendix for screenshoots in English. In Bonn subjects were invited via ORSEE (Greiner, 2004).
} 
Table 1: Treatments

\begin{tabular}{ccccc}
\hline & Location & Punishment & Subjects & Ind. Groups \\
\hline 1 & Shanghai & Asymmetric & 48 & 24 \\
2 & Shanghai & Symmetric & 48 & 24 \\
3 & Bonn & Asymmetric & 48 & 24 \\
4 & Bonn & Symmetric & 48 & 24 \\
\hline Total & & & 192 & 96 \\
\hline
\end{tabular}

At the beginning of each session, subjects were seated in cabins, instructions were distributed and read out. ${ }^{19}$ All subjects received the same instructions which included the terms favor and punishment, but, to focus solely on the effect of alternative punishment regimes, no references to bribing or criminal activities were given. ${ }^{20}$

Thereafter, subjects were informed about their randomly determined role (proposer (payer of the bribe) or responder (receiver of the bribe)) and had to decide in the corresponding role. Only after the first period, subjects were informed that they would play the same game in the same role with the same anonymous partner for additional 10 rounds. To gather a sufficient amount of data, the strategy method (Selten, 1967) was adopted for the second and third stages. That is, each responder had to decide, conditional on receiving an offer, and each proposer had to decide whether to report conditional on a favor being refused. ${ }^{21}$ However, proposers' reporting decisions were only elicited if the proposer submitted an offer. At the end of each round, subjects were informed about the actual decisions and their payoffs. At the end of each session, risk attitudes were elicited (Holt and Laury, 2002). ${ }^{22}$

Each session lasted less than two hours including the time for payments. The final payoff consists of the payoff from period 1 and a random period selected from periods 2-11. The exchange rates from taler into the corresponding currency were adjusted to the hourly wage of a student

\footnotetext{
${ }^{19}$ To avoid translation errors regarding the task and notions, instructions and computer screens were translated from English into the corresponding language and afterwards back-translated into English by a different person (Brislin, 1970). For an English version of the instructions, refer to the appendix.

${ }^{20}$ The literature on framing effects in bribery experiments is inconclusive. Bribery rates dropped in a one-shoot game if it was framed as a petty corruption scenario (Barr and Serra, 2007), but no decrease was observed in a repeated setting (Abbink and Hennig-Schmidt, 2006). Nevertheless, this question is not of big importance for our study as we can assume that the effect of framing should not interact with our research question.

${ }^{21}$ Brandts and Charness (2011) investigate the robustness of the strategy method in comparison to the directresponse method. In their meta-study every significant treatment effect that was found with the strategy method was also observed with the direct-response method.

${ }^{22}$ This test was motivated by the fact that the design exposes participants to stochastic risk (if the favor is granted) and to strategic risk (will the recipient accept? will the favor be granted?).
} 
helper (Bonn: 0.06 Euro per taler; Shanghai 0.14 Yuan) ${ }^{23}$ and each participant received a show-up fee of 4 Euros in Bonn and 9 Yuan in Shanghai. Earnings were paid out in cash directly after the experiment and average payoffs were 20 Euros in Bonn and 45 Yuan in Shanghai.

\subsection{Behavioral Predictions}

The two treatments of our experiment allow us to investigate the effects of asymmetric and symmetric punishment by comparing the frequencies of bribe attempts, of accepted bribes, of granted favors, and of reports to the authorities between the two treatments. However, standard theory under the assumption that players' behavior is purely money-maximizing and that this is common knowledge predicts no bribery at all and thus no differences between the two punishment regimes.

This game-theoretical solution is driven by the assumption that subjects are solely motivated by their own payoffs, thus a payer would never engage in costly reporting to the authorities if the bribe was accepted but no favor granted. For this reason, it does not matter whether the punishment for the payer is high (symmetric punishment) or relatively low (asymmetric punishment). A moneymaximizing briber never uses reporting to take revenge. From this point, the unique subgameperfect equilibrium can be derived by backward induction. A rational receiver would anticipate the payer's behavior and therefore accept the money without granting a favor. Thereby, he earns more in comparison to rejecting the offer. Furthermore, he does not risk external detection and punishment which he would face if he granted the favor. A rational payer would foresee this rationale and decide not to offer a bribe to the receiver. Thus, in both treatments, no bribery at all should occur. ${ }^{24}$

Nevertheless, bribery occurs in lab experiments applying games with similar equilibria (e.g., Abbink et al. (2002)), and of course outside the lab. In addition, behavioral experiments repeatedly demonstrated the willingness to engage in costly punishment (e.g., Güth et al. (1982) ${ }^{25}$, Fehr and Gächter (2000), and Henrich et al. (2006)). These results are very stable and even hold in related bribery experiments (Lambsdorff and Frank, 2011). The tendency to punish unkind behavior has been linked to distributional preferences as well as fairness intentions (Fehr and Schmidt (1999), Bolton and Ockenfels (2000), Falk and Fischbacher (2006)). Given this evidence, we formulate

\footnotetext{
${ }^{23}$ Alternatively, one might have kept the exchange rate fixed, but given differences in purchasing power this would have resulted in running a high stake experiment in China.

${ }^{24}$ This result holds for risk-neutral and risk-averse subjects.

${ }^{25}$ Early evidence can be found in the the results of ultimatum games. There responders typically reject offers of less than twenty percent of the total amount available. Responders are thus willing to punish unfair behavior, even at a financial cost to themselves. And this response seems to be expected and anticipated by proposers; they typically offer a substantial portion of the sum to be divided - ordinarily forty to fifty percent. See Güth et al. (1982, 367, 371-72, 375 tbls.4 \& 5); Kahneman et al. (1986, S285, S291 tbl.2), summarized in Jolls et al. (1998).
} 
our first hypothesis about subjects' behavior:

Hypothesis 1: Bribe attempts, positive reciprocity (granting favors), as well as negative reciprocity (reporting to the authorities) are observed under both punishment regimes.

In our setup, self-reporting can be stimulated by inequality aversion (Fehr and Schmidt, 1999) and negative reciprocity (Falk and Fischbacher, 2006). Both concepts explain the willingness to engage in costly punishment. In the case of asymmetric punishment, the cost of self-reporting is reduced for the payer. Thus, retaliating upon the receiver for taking the bribe but granting no favor becomes much cheaper for the payer. In terms of Fehr and Schmidt (1999), this means that the cost for reducing payoff inequalities between payer and receiver decreases. Depending on the degree of inequality aversion, this should lead to more reporting in the case of asymmetric punishment. ${ }^{26}$ Therefore, we formulate our second hypotheses as follows:

Hypothesis 2: The reduced cost of self-reporting leads to more reports under asymmetric punishment.

It has been shown that in voluntary contribution mechanisms cooperation increases in the effectiveness of punishment, i.e., lower costs per punishment point (c.f. Nikiforakis and Normann (2008), Egas and Riedl (2008)). A similar effect is present in our experimental study: retaliation and therefore the enforcement of cooperation if the bribe was accepted is cheaper under asymmetric punishment. In this case, even a rational self-centered receiver will grant the favor if he believes that the probability of being matched with a retaliating subject is high enough. As formulated in our second hypotheses, we expect more self-reports under asymmetric punishment, and therefore accepting the bribe without granting the favor becomes less attractive for receivers under asymmetric punishment. ${ }^{27}$

Hypothesis 3: The threat of more self-reports under asymmetric punishment leads to more favors granted if the bribe is accepted.

If asymmetric punishment leads to more favors granted, more payers benefit from offering bribes. As a result, we expect payers to make more offers under asymmetric punishment than under symmetric punishment. ${ }^{28}$

\footnotetext{
${ }^{26}$ In fact, already a subject having the joint combination of the smallest degree of envy and guilt $(\alpha=0.5, \beta=$ 0.25; taken from Fehr and Schmidt (1999)) should report under asymmetric punishment, but not under symmetric punishment. Fehr and Schmidt (1999) assume that 30\% of subjects have such a combination of $\alpha$ and $\beta$.

${ }^{27}$ Under both punishment regimes, a rational receiver would grant the favor if the reporting probability were higher than the external detection rate. Note that a population with a degree of envy and guilt as small as reported in footnote $26(30 \%)$ already results in a higher frequencies of self-reports than the detection probability under asymmetric punishment, but not under symmetric punishment.

${ }^{28} \mathrm{We}$ refrain from modeling the bribery game as a signaling game with two different types of payers (reporting and not reporting). In a signaling game, one could investigate whether subjects who are not reporting mimic reporting subjects by making an offer to the receiver. Yet the equilibria of the ensuing signaling game could only be derived if
} 
Hypothesis 4: More bribe attempts are made by payers under asymmetric punishment.

Given the above hypotheses we expect more implemented bribes under asymmetric punishment than under symmetric punishment, resulting in our fifth hypothesis:

Hypothesis 5: We expect more concluded bribes under asymmetric punishment.

\section{Results}

We now turn to the results of the experiment. We will start with the investigation of self-reporting behavior. Afterwards we will turn to the differences in rejections and favors between the two treatments. For our analysis, we split this choice into the two logical steps: 1.) Shall I accept the bribe and 2.) If so, shall I grant the favor? Thereafter the frequencies of offers are compared between the two punishment regimes. Finally, this section concludes with an analysis of successfully and unsuccessfully conducted bribes.

\subsection{Self-Reporting}

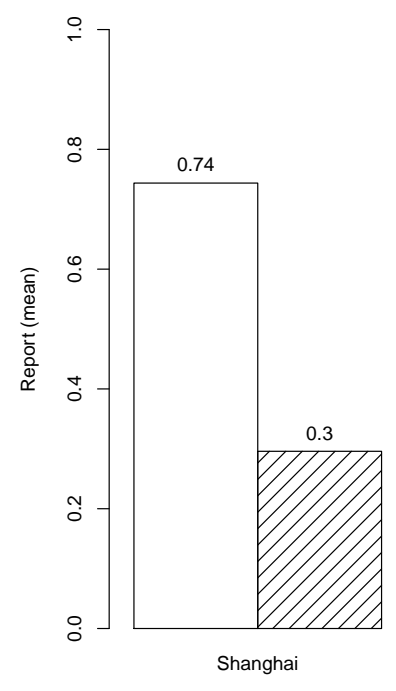

(a) Frequency of reporting

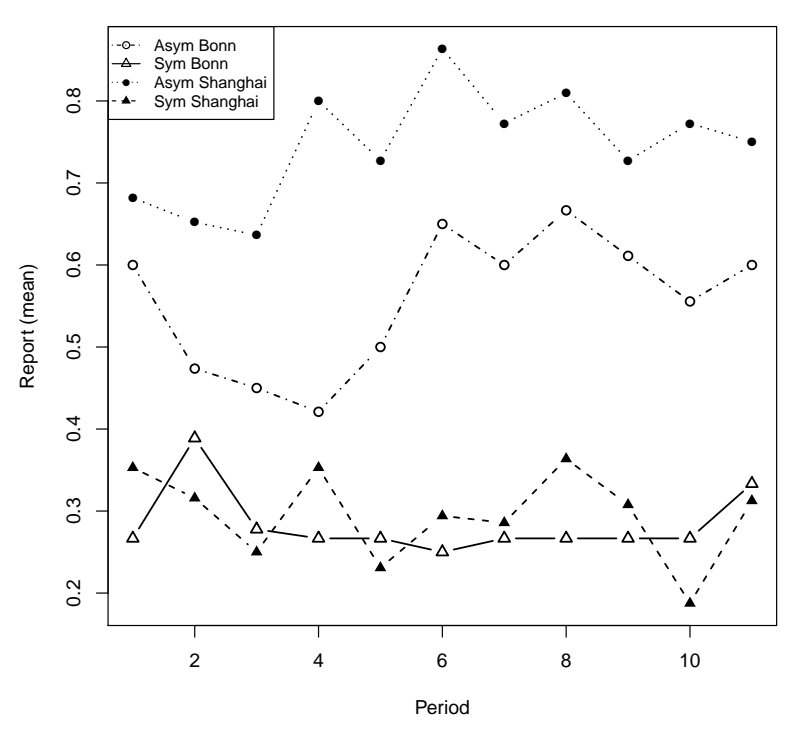

(b) Reporting over period

Figure 3: Reporting by treatment and country

the exact proportion of self-reporting payers was determined outside the experiment, which would make one of our main dependent variables pointless. Therefore, we do not deem this modeling strategy appropriate. 
Figure 3 gives the frequencies of self-reporting decisions over all participants and periods for the two punishment regimes in Bonn and Shanghai. Over all rounds and both locations, significantly more self-reports occur under asymmetric punishment than under symmetric punishment ( $p<0.01$, two-sided Man-Whitney u-test). This significant difference is already present in the first round ( $p<0.01$, two-sided Fisher's exact). Also, the result holds for both locations separately: in Shanghai, in $74 \%$ of all cases payers decided to report under asymmetric punishment, while only $30 \%$ did so under symmetric punishment (overall: $p<0.01$, two-sided Mann-Whitney u-test; first round: $p<0.05$, two-sided Fisher's exact). A similar picture is present in Bonn, there, in 56\% of all cases, a payer decided to report if an asymmetric punishment regime was present, while in a significantly lower $28 \%$ of all cases, payers reported if a symmetric punishment regime was present (overall: $p<0.05$, two-sided Mann-Whitney u-test; first round: $p<0.1$, two-sided Fisher's exact). These findings are in line with our second hypothesis.

Model 1 of Table 2 basically repeats this nonparametric test. The proposer is much more likely to punish the recipient, by reporting to the authorities, if the recipient has broken the deal and not granted the favor after having cashed in the bribe. Of course, a money-maximizing proposer would not do so. She is still better off if the authorities never learn about corruption. Yet since the sanction they expect is low, a considerable number of proposers would rather accept this small loss than allow the recipient to let them down. Apparently, the willingness of proposers to punish unfair recipients is pronounced, and it is sensitive to the price of punishment.

Table 2: Reporting to the Authorities

\begin{tabular}{|c|c|c|}
\hline & $\begin{array}{c}\text { Model } 1 \\
\text { Reporting }\end{array}$ & $\begin{array}{c}\text { Model } 2 \\
\text { Reporting }\end{array}$ \\
\hline Symmetric punishment & $-9.152^{* * *}$ & $-9.927^{* * *}$ \\
\hline Germany & -1.453 & -1.755 \\
\hline \#Favor granted & & 0.221 \\
\hline Symmetric*\#Favor granted & & $-0.725^{* *}$ \\
\hline Period & 0.082 & 0.080 \\
\hline Constant & $3.945^{* *}$ & $4.900^{* * *}$ \\
\hline Observations & 776 & 713 \\
\hline P model & $<0.001$ & $<0.001$ \\
\hline
\end{tabular}


Actually, the difference between both treatments is huge. Model 1 predicts that proposers next to never report to the authorities if let down when punishment is symmetric (the predicted probability is below 1\%), while they almost always punish an unfaithful recipient if the asymmetry of criminal law makes this cheap (the predicted probability is 97\%). Further note that proposers do not have to learn this through experience; the time trend is insignificant. By contrast, model 2 shows an effect of experience that is confined to the symmetric treatment. The more often other recipients have granted the favor in the past, the smaller the probability of reporting is now. This suggests that proposers learn a certain degree of forgivingness.

\subsection{Favors}

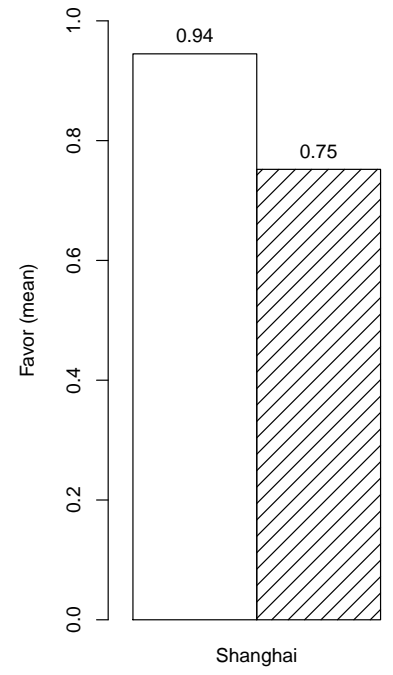

(a) Frequency of favor

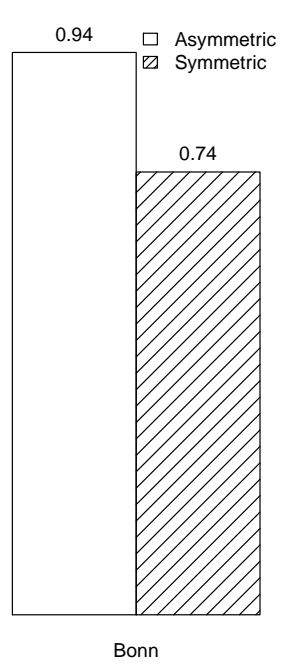

Figure 4: Favor by treatment and country

Figure 4 shows that more favors are granted under asymmetric punishment. This difference is not only significant for the overall means ( $p<0.01$, two-sided Mann-Whitney u-test), but already in the first round ( $p<0.01$, two-sided Fisher's exact). This finding confirms our third hypothesis. In Bonn, 94\% chose to return a favor under asymmetric punishment and 74\% did so in the symmetric treatment (Figure 4(a)). Results in Shanghai are very similar, and the overall difference is significant at both locations (both: $p<0.05$, two-sided Mann-Whitney u-test). 
Besides treatment effects, another finding worth mentioning is the extremely strong tendency of receivers to return the favor. In both treatments at both locations, favors are granted on more than $70 \%$ of all occasions. This observation is in accordance with the previous experimental finding that trust and reciprocation is a prominent feature of bribery and leads to violation of equilibrium behavior (Abbink et al., 2002).

Our parametric analyses confirm the above results. Model 1 in Table 3 shows two separate effects: recipients anticipate that proposers are much more likely with asymmetric punishment to report to the authorities. This leads to the significant treatment effect. If they have experienced in the past that proposers do indeed rely on this cheap punishment technology, this makes refusing the favor upon accepting the bribe even less likely. Note, however, that we estimate a logistic regression. While the coefficient of a single experience with reporting to the authorities looks large, actually even without any such experience the predicted probability of granting the favor is already $99.09 \%$. If punishment is asymmetric, corrupt deals are almost perfectly enforced.

Model 2 shows that recipients are all the more likely to grant the favor the more they are riskaverse. Note that recipients actually face two competing risks. If they refuse the favor, they risk that the proposer reports to the authorities. If they grant the favor, corruption may be detected by the authorities on their own initiative, in which case the recipients also face the sanction. From the fact that the regressor is significantly positive we learn that recipients are more afraid of the punishing sentiments of proposers than of surveillance by the authorities.

Table 3: Granting the Favor

\begin{tabular}{|c|c|c|}
\hline & $\begin{array}{c}\text { Model } 1 \\
\text { Favor }\end{array}$ & $\begin{array}{c}\text { Model } 2 \\
\text { Favor }\end{array}$ \\
\hline Symmetric punishment & $-2.453^{* *}$ & $-2.940^{* *}$ \\
\hline Germany & 0.404 & -0.018 \\
\hline \#Reported to authorities & $1.646^{* *}$ & $1.648^{* *}$ \\
\hline Period & $-0.166^{* *}$ & $-0.200^{* *}$ \\
\hline Risk aversion & & $0.615^{*}$ \\
\hline Constant & $5.397^{* * *}$ & $3.437^{*}$ \\
\hline Observations & 881 & 742 \\
\hline P model & 0.0002 & 0.0009 \\
\hline
\end{tabular}




\subsection{Rejections}

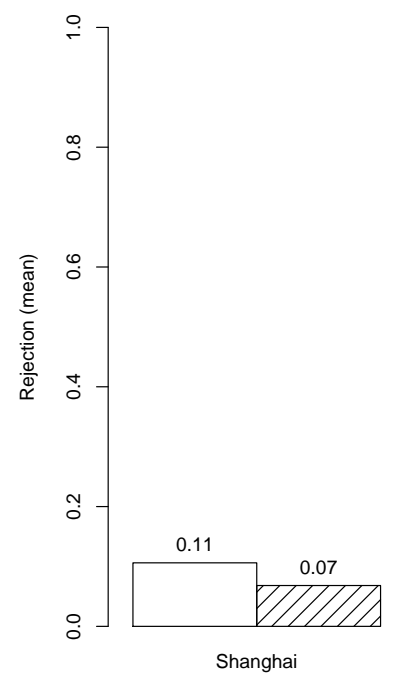

(a) Frequency of rejection

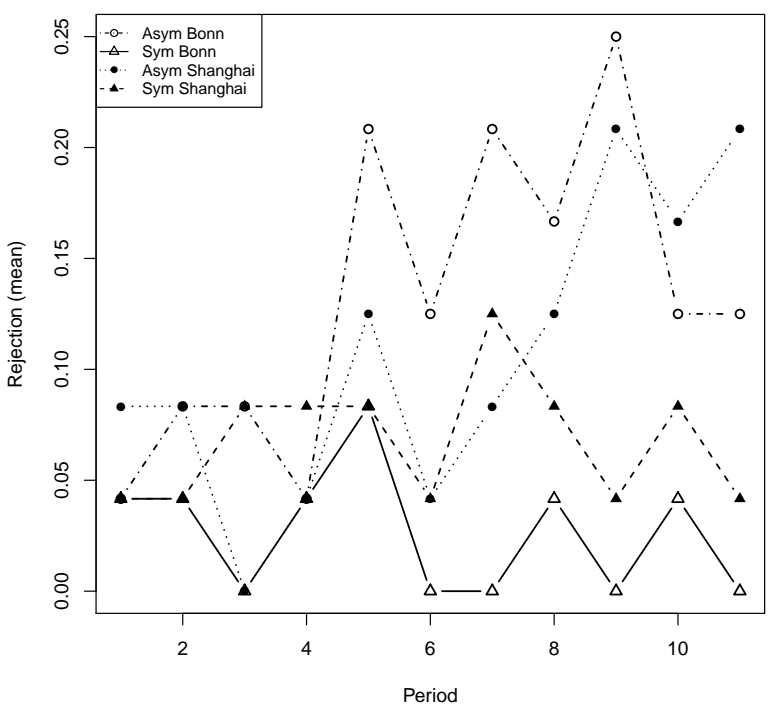

(b) Rejection over period

Figure 5: Rejection by treatment and country

Figure 5(a) gives the mean rejection rates per punishment regime and location. In Bonn and Shanghai, more rejections occur under asymmetric punishment. However, this difference is not large and only weakly significant ( $p<0.1$, two-sided Mann-Whitney u-test). Figure 5(b) reveals that the difference between the rejection rates under symmetric and asymmetric punishment evolves only over time. While the difference is not significant in the early rounds of the experiment, it becomes significant for period 9 ( $p<0.01$, two-sided Fisher's exact) and period $11(p<0.05$, two-sided Fisher's exact).

Model 1 of Table 4 confirms the nonparametric test: if punishment is asymmetric, offers are more likely to be rejected. ${ }^{29}$ The significant time trend shows that corrupt deals are slightly less likely among experienced players. Model 2 shows that it has a significant effect on the future instance of corruption if a proposer has taken revenge on a recipient. Such responders are more likely to resist corrupt offers the proposers make in the future. Yet one should once more not be misled by the apparent size of the coefficient. If punishment is asymmetric, so that reporting to

\footnotetext{
${ }^{29}$ In the experiment, receivers simultaneously chose between three options: rejecting the offer, accepting the offer and granting the favour, accepting the offer and refusing the favour. In our regressions, we split this choice into the two logical steps: shall I accept the bribe? If so, shall I grant the favour? If we rerun the regressions with a multinomial logit model, results look similar.
} 
Table 4: Rejecting the Offer

\begin{tabular}{lccc}
\hline & $\begin{array}{c}\text { Model 1 } \\
\text { Rejection }\end{array}$ & $\begin{array}{c}\text { Model 2 } \\
\text { Rejection }\end{array}$ & $\begin{array}{c}\text { Model 3 } \\
\text { Rejection }\end{array}$ \\
\hline Symmetric punishment & $-1.468^{*}$ & $-1.529^{*}$ & $-2.061^{*}$ \\
Germany & -0.804 & -0.653 & -1.295 \\
\#Offers & & $-0.226^{+}$ & -0.265 \\
\#Reported to authorities & & $1.027^{*}$ & $1.152^{*}$ \\
\#Detection & & 0.379 & 0.359 \\
Period & $0.135^{* *}$ & $0.248^{* *}$ & $0.353^{*}$ \\
Risk aversion & & & 0.365 \\
Constant & $-4.104^{* * *}$ & $-4.437^{* * *}$ & $-6.671^{* * *}$ \\
\hline Observations & 1056 & 960 & 810 \\
P model & 0.0042 & 0.0066 & 0.0036 \\
\hline
\end{tabular}

Random effects logit regressions, Hausman test significant, but problem can be remedied by Hausman Taylor, treating \# of past offers, past reports to the authorities and past detection as endogenous, subsequent second Hausman test insignificant. Risk aversion: switching point in Holt/Laury test, if participant was consistent. ${ }^{+} p<0.1,{ }^{*} p<0.05,{ }^{* *} p<0.01,{ }^{* * *} p<0.001$.

the authorities is not heroic, the predicted probability of an offer being rejected is as low as $2.2 \%$. After the recipient has once been reported to the authorities, the rejection probability goes up to $8.3 \%$. Even after two such experiences, it is only $13 \%$. Interestingly, the frequency of detection in case the proposer has granted the favour has no significant influence on her later willingness to strike new corrupt deals. There is a small, and only weakly significant, effect of the number of offers this recipient has received in the past. Risk aversion does also not determine the decision to reject bribery offers (model 3).

\subsection{Offers}

Figures 6(a) and (b) show that at both locations more offers were made under asymmetric than under symmetric punishment. Overall, the differences between offers under symmetric and asymmetric punishment are significant (overall: $p<0.01$, two-sided Mann-Whitney u-test), which confirms our fourth hypothesis. However, first-round behavior differs significantly between the two punishment regimes only in Shanghai ( $p<0.01$, two-sided Fisher's exact).

Model 1 of Table 5 confirms that bribery is less likely if punishment is symmetric. The regression also shows that experienced participants are slightly less likely to offer a bribe. From models 


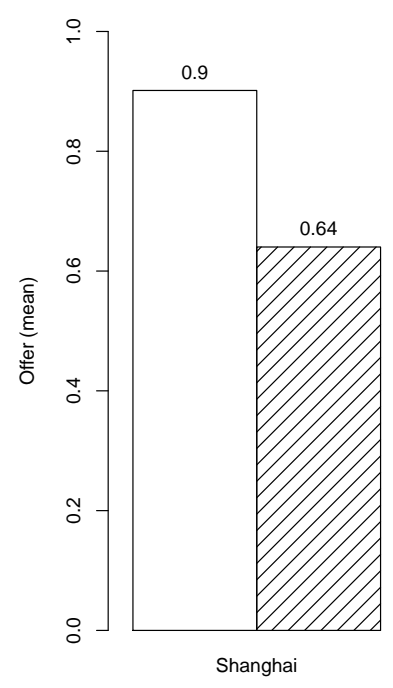

(a) Frequency of offer

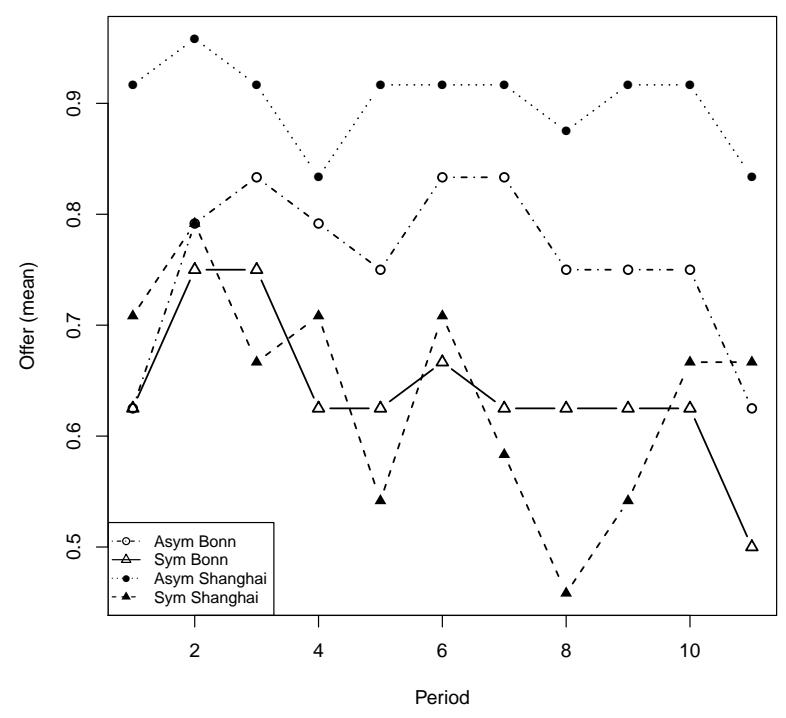

(b) Offer over period

Figure 6: Offer by treatment and country

2 and 3 we learn that proposers are highly sensitive to the experiences they are making. If bribery has worked out in that the expected favor has been granted, proposers become more likely to offer a bribe again in the future. By contrast, the more often they have been detected, the less they are likely to engage in corruption in the future. Finally, from model 4 one sees that the more a proposer is risk-averse, the more she refrains from bribing an official.

\subsection{Effect on Deals}

Ultimately, from a normative perspective, neither offers nor rejections per se matter. Rather, the law wants to deter corrupt deals. This can mean two things: deals should not be struck, or they should not be implemented. In the former perspective, the number of offers that are not rejected is critical. In the latter perspective, it matters whether a deal is struck and the favor is granted.

From Figure 7, it is easy to see that in China deals were implemented more frequently with asymmetric punishment. This is supported by a Wilcoxon ranksum test $(p<0.01$, two-sided Mann-Whitney u-test). In Germany, this effect is weaker and not significant. Overall, the treatment effect on deals implemented is significant ( $p<0.05$, two-sided Mann-Whitney u-test) and in line with our fifth hypothesis.

As the regressions in Table 6 show, it takes time for treatment effects to unfold. Participants do 
Table 5: Offering a Bribe

\begin{tabular}{lcccc}
\hline & $\begin{array}{c}\text { Model 1 } \\
\text { Offer }\end{array}$ & $\begin{array}{c}\text { Model 2 } \\
\text { Offer }\end{array}$ & $\begin{array}{c}\text { Model 3 } \\
\text { Offer }\end{array}$ & $\begin{array}{c}\text { Model 4 } \\
\text { Offer }\end{array}$ \\
\hline Symmetric punishment & $-2.053^{* *}$ & $-1.242^{* *}$ & $-1.217^{* *}$ & $-1.576^{* *}$ \\
Germany & -0.910 & -0.391 & -0.481 & 0.244 \\
\#Favor & & $0.621^{* * *}$ & $0.768^{* * *}$ & $0.834^{* * *}$ \\
\#Detection & & & $-0.627^{* *}$ & $-0.632^{*}$ \\
Period & $-0.101^{* *}$ & $-0.360^{* * *}$ & $-0.332^{* * *}$ & $-0.352^{* * *}$ \\
Risk aversion & & & & $-0.464^{* *}$ \\
Constant & $4.297^{* * *}$ & $2.931^{* * *}$ & $2.934^{* * *}$ & $5.315^{* * *}$ \\
\hline Observations & 1056 & 960 & 960 & 800 \\
P model & 0.0002 & $<0.001$ & $<0.001$ & $<0.001$ \\
\hline
\end{tabular}

Random effects logit regressions, Hausman test insignificant on model 1, but significant on the remaining models. Problem can be remedied by Hausman Taylor, treating \# of past favors and past detection as endogenous, subsequent second Hausman test insignificant. Risk aversion: switching point in Holt/Laury test, if participant was consistent.

${ }^{*} p<0.05,{ }^{* *} p<0.01,{ }^{* * *} p<0.001$.

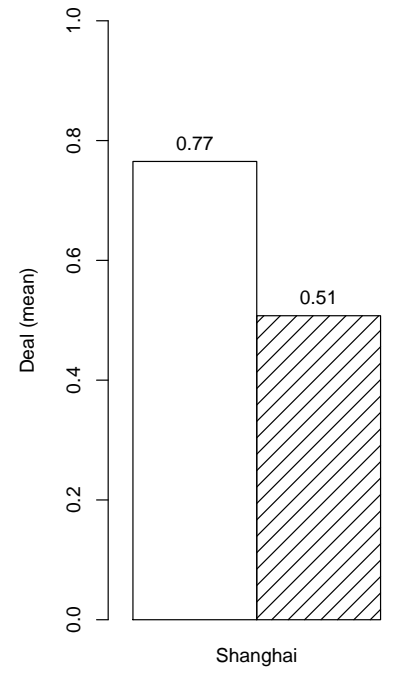

(a) Frequency of deal

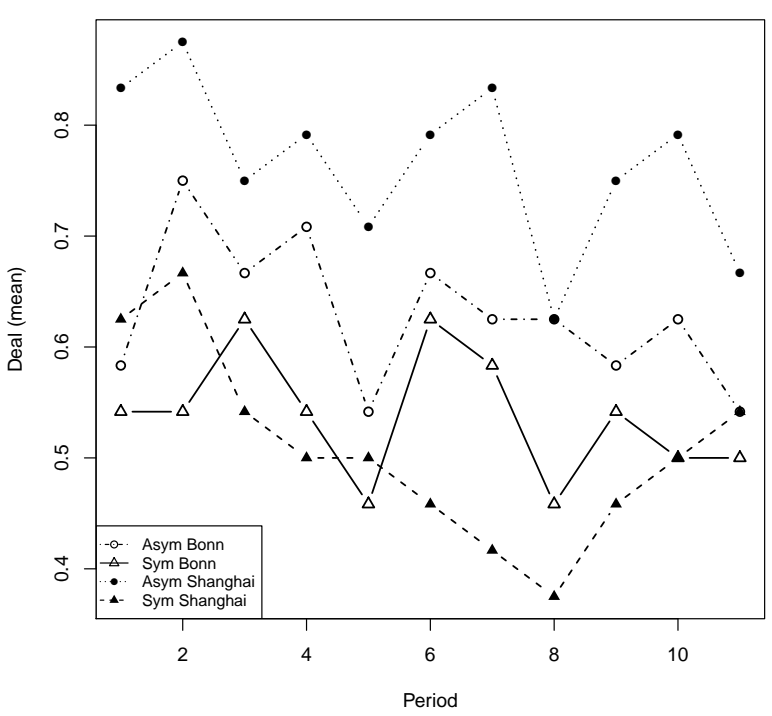

(b) Deal over period

Figure 7: Deal by treatment and country 
not immediately adopt a definite strategy. Actually, the more experience they have, the more they become cautious. This follows from the fact that the time trend is negative in both regressions, and highly significant. If we control for the time trend, we find that there is significantly less corruption if punishment is symmetric. Significantly less deals are implemented (model 2). There is also a weakly significant effect of the punishment scheme on the number of deals concluded (model 1).

Table 6: Deals Concluded and Deals Implemented

\begin{tabular}{lcc}
\hline & $\begin{array}{c}\text { Model 1 } \\
\text { Deals concluded }\end{array}$ & $\begin{array}{c}\text { Model 2 } \\
\text { Deals implemented }\end{array}$ \\
\hline Symmetric punishment & $-0.952^{+}$ & $-1.411^{*}$ \\
Germany & -0.432 & -0.475 \\
Period & $-0.113^{* * *}$ & $-0.092^{* * *}$ \\
Constant & $2.734^{* * *}$ & $2.318^{* * *}$ \\
\hline Observations & 1056 & 1056 \\
P model & 0.0006 & 0.0011 \\
\hline Random effects logit regressions, Hausman test insignificant. ${ }^{+} p<0.1,{ }^{*} p<0.05,{ }^{* *} p<$ \\
$0.01,{ }^{* * *} p<0.001$.
\end{tabular}

The game-theoretic logic suggests that participants react to the experiences they are making in the spirit of backward reasoning. If proposers frequently punish receivers for breaking the deal by reporting to the authorities, deals should be kept more faithfully. If deals are frequently rejected or broken, proposers should become more hesitant to offer a bribe. This is indeed what we find.

\section{Conclusion}

In this paper, two different punishment regimes for collusive bribery were experimentally investigated. These punishment regimes are the two prevalent ones in major legal orders with either symmetric punishment of briber and receiver or asymmetric punishment favoring the briber. Under both punishment regimes, bribery was observed, but less implemented deals were observed under a symmetric punishment regime. Interestingly, these results hold for our experiments in China and Germany, suggesting that we have found a general effect that is not conditional upon a specific social, political, economic, or legal culture.

If the situation we have tested in our experiment captures the essence of the collusive interaction between a briber and an official, we have a clear message for policymakers. If bribers are punished more leniently, there is more corruption. Interested parties have less hesitance to approach a public 
official and offer a side payment in exchange for an expected violation of their professional duties. Most importantly, if punishment is asymmetric, bribers have no longer reason to fear that they will be let down by the official. In principle, this risk is pronounced. Since corrupt deals are illegal, the briber cannot take the official to court if the official cashes the bribe in but does not grant the expected favor. Yet the asymmetry of punishment provides bribers with a fairly cheap technology for punishing dishonest officials. If he breaks the implicit deal, at a relatively small cost for himself the briber may impose severe harm on the official. Our experiment shows that bribers indeed use this technology, and that this is rightly anticipated by most officials. Fairness preferences, in the form of punishing sentiments, therefore lead to the almost perfect enforcement of the corrupt deal.

It is true that a few more officials reject the bribe if punishment is asymmetric. Seemingly, the argument brought forward by Susan Rose-Ackerman applies: "Because it takes two to enter into a corrupt deal, the crime will not occur if the law can deter at least one of the parties" (RoseAckerman, 1999). Yet the size of the effect is rather modest. More importantly, rejections become somewhat more frequent if the official has experienced that a proposer has indeed been willing to endure the small sanction for herself, for the sake of punishing this official when she has broken the corrupt deal. This indicates that asymmetric punishment chiefly deters such corrupt deals that would not have been implemented in the first place. What might look desirable at first glance turns out to be a screening device. Only those corrupt deals that both sides are willing to implement are struck.

It thus seems that, from a policy perspective, punishing the briber in collusive bribery more leniently is a very bad idea. Our results are not necessarily transferrable to harassment bribes. Both types of bribery (collusive and extortionary) differ significantly in terms of who bears the burden of harm. In collusive bribery, bribers and corruptor enjoy mutual benefits while harming the public. With harassment bribes the public official exploits the briber while the public is only harmed indirectly. Thus, both situations differ on moral grounds and strategic considerations. We demonstrated that asymmetric punishment can increase the bound between briber and bribee in collusive bribery, but in extortionary bribes it might actually reduce the bound as reported in Abbink et al. (2012). This message not only matters for a legislator contemplating to introduce the asymmetry openly. It also speaks to the temptation silently to introduce such an asymmetry in jurisprudence. In most countries, this is feasible since the legislator only determines a lower and an upper bound, without precisely determining the severity of the criminal sanction. The courts might exploit the partial indeterminacy of the sanction to sneak in asymmetry, in reaction to retributive sentiments. 


\section{References}

Abbink, K., Irlenbusch, B. and Renner, E. 2002. An Experimental Bribery Game, Journal of Law, Economics and Organization 18, 428 - 454.

Abbink, K., and Hennig-Schmidt, H. 2006. Neutral versus Loaded Instructions in a Bribery Experiment, Experimental Economics 9, 103-121.

Abbink, K. and Serra, D. 2012. Anti-corruption policies: Lessons from the lab in: New Advances in Experimental Research on Corruption, Research In Experimental Economics Volume 15, edited by Serra and Wantchekon, Bingly: Emerald Group Publishing, June 2012.

Abbink, K., Dasgupta, U., Gangadharan, L., and Jain, T. 2012 Letting the Briber Go Free: An Experiment on Mitigating Harassment Bribes, Working Paper

Apesteguia, J., Dufwenberg, M., and Selten, R., 2007. Blowing the whistle, Economic Theory 31.

Banuri, S., and Eckel, C. 2009. The Effects of Sanctions on Bribery: US versus Pakistan, CBEES Working Paper Series 09-01.

Barr, A., and Serra, D., 2007. Externality and framing effects in a bribery experiment, Working paper 2007-16, Centre for the Study of African Economies, University of Oxford.

Barr, A., and Serra, D., 2010. Culture and Corruption: An experimental analysis, The Journal of Public Economics, 94(11-12), 862-869.

Basu, K., 2011. Why for a Class of Bribes, the act of Giving should be treated legal, Working Paper 17201211 DEA, Ministry of Finance, Government of India.

Becker, G., 1968. Crime and Punishment: An Economic Approach, Journal of Political Economy 76, 169-217.

Bentham, J., 1802. Theory of Legislation, Trubner \& Co., London, 1864.

Bohlander, M., 2008. The German Criminal Code: A Modern English Translation, Hart Publishing, Oxford.

Bolton, G. and Ockenfels, A, 2008. ERC: A Theory of Equity, Reciprocity, and Competition, The American Economic Review 90, pp. 166-193. 
Brandts, J., and Charness, G. 2011. The Strategy Versus the Direct-Response Method: a First Survey of Experimental Comparisons., Experimental Economics, 14(3), pp. 375-398

Brislin, R. W. 1970. Back-translation for cross-cultural research, Journal of Cross-cultural Psychology, 1(3), 185-216.

Buccirossi, P., and Spagnolo, G. 2006. Leniency policies and illegal transactions, Journal of Public Economics 90, 1281-1297.

Cameron, L., Chaudhuri, A., Erkal, N. and Gangadharan, L. 2009. Propensities to Engage in and Punish Corrupt Behavior: Experimental Evidence from Australia, India, Indonesia and Singapore, Journal of Public Economics 93, 843-851.

Doerr, M. T., 2009. Not Guilty? Go to Jail, 41 Columbia Human Rights Law Review 235.

Dufwenberg, M., and Spagnolo, G., 2011. Legalizing Bribes, Working Paper.

Egas, M. and Riedl, A., 2008. The economics of altruistic punishment and the maintenance of cooperation. Proceedings of the Royal Society B 275, 871-878.

Falk, A. and Fischbacher, U., 2006. A theory of reciprocity. Games and Economic Behavior 54, $293-315$.

Fehr, E. and Gächter, S., 2000. Fairness and retaliation: The economics of reciprocity. Journal of Economic Perspective 14, 159-181.

Fehr, E. and Schmidt, K. M., 1999. A theory of fairness, competition, and cooperation. The Quarterly Journal of Economics 114, 817-868.

Fischbacher, U., 2007. z-Tree. Zurich Toolbox for Ready-made Economic Experiments, Experimental Economics 10, 171-178.

Geng, H. and Hennig-Schmidt, H., 2011. Sensitivity to Corruption: An Experimental Investigation in China, mimeo.

Greiner, B. 2004. An online recruitment system for economic experiments, In: Krämer, H. and V. Macho (Ed.), GWDG Bericht 63. Forschung und wissenschaftliches Rechnen 2003. Ges. fuer Wiss. Datenverarbeitung Goettingen, pp. 79-93.

Güth, W., Schmittberger, R. and Schwarze, B., 1982. An Experimental Analysis of Ultimatum Bargaining, Journal of Economic Behavior and Organization 3. 
Henrich J., et al., 2006. Costly Punishment Across Human Societies, Science Vol 312(23).

Holt, A. C. and Laury, K. S., 2002. Risk Aversion and Incentive Effects, The American Economic Review. 92(5), 1644-1655.

Jolls, C., Sunstein, R. C., and Thaler, R., 1998. A Behavioral Approach to Law and Economics, Stanford Law Review 50, 1471-1550.

Kahneman, D., Knetsch, L. J., Thaler, H. R. 1986. Fairness and the Assumptions of Economics, 59 J. BUS.

Kingston, C., 2007. Parochial corruption, Journal of Economic Behavior and Organization 63(1), 73-87.

Knack, S., and Keefer, P., 1995. Institutions and Economic Performance: Cross-Country Tests Using Alternative Institutional Measures, Economics and Politics 7, 207-227.

Lambsdorff, J.G., 2006. Causes and consequences of corruption: what do we know from a crosssection of countries?, In Rose-Ackerman, S. (Ed.), International Handbook on the Economics of Corruption. Edward Elgar, Cheltenham, UK, pp. 351.

Lambsdorff, J. G., and Frank, B. 2011. Corrupt reciprocity - Experimental evidence on a men's game, International Review of Law and Economics 31(2), 116-125.

Lambsdorff, J. G., and Nell, M. 2007. Fighting Corruption with Asymmetric Penalties and Leniency, CeGE-Discussion Paper 59.

Mauro, P., 1995. Corruption and Growth, Quaterly Journal of Economics 110, 681-721.

Nell, M., 2007. Strategic Aspects of Voluntary Disclosure Programs for Corruption Offenses, Discussion paper, University of Passau No. V-52-07.

Nikiforakis, N. and Normann, H. T. 2008. A comparative statics analysis of punishment in publicgood experiments, Experimental Economics 11, pp. 358-369.

Rose-Ackerman, S., 1999. Corruption and Government: Causes, Consequences and Reform, Cambridge University Press, New York.

Scott, J.C., 1972. Comparative Political Corruption. Prentice-Hall, Englewoods Cliffs. 
Selten, R., 1967. Die Strategiemethode zur Erforschung des eingeschränkt rationalen Verhaltens im Rahmen eines Oligopolexperiments. In: Sauerman, H. (Ed.), Beiträge zur experimentellen Wirtschaftsforschung. J.C.B. Mohr (Paul Siebeck), Tübingen, pp. 136-168.

Serra, D., and Wantchekon, L. 2012 (eds). New Advances in Experimental Research on Corruption, Research In Experimental Economics Volume 15, Bingly: Emerald Group Publishing, June 2012.

Serra, D. 2006. Empirical Determinants of Corruption: A Sensitivity Analysis, Public Choice 126, 225256.

Shen J., 1911. Comment on equal punishment for bribery parties(Yu Shou Tong Ke Yi), Ji Yi Wen Cun, Vol. 6.

Schikora, J. S. 2011. Bringing Good and Bad Whistle-Blowers to the Lab. Munich Discussion Paper 2011, no. 4, 1-48.

Schulze, G. G., and Frank, B. 2003. Deterrence versus Intrinsic Motivation: Experimental Evidence on the Determinants of Corruptibility, Economics of governance 4, 143-160.

Spagnolo, G., 2005. Divide et Impera: Optimal Leniency Programs, C.E.P.R. Discussion Paper No. 4840.

Spratling, G. R., 1999. Making companies an offer they shouldn't refuse: the antitrust division's corporate leniency policy? - An update, Antitrust Division, U.S. Department of Justice, available via http://www.usdoj.gov/atr/public/speeches/2247.htm, accessed on 2 Jan 2011. 


\section{Appendix}

\section{A Instruction ${ }^{30}$}

\section{Welcome to the Experiment}

Welcome to this decision experiment. Please read the following instructions carefully. The Experiment will be done anonymously, so that you will not be informed with which of the other participants you interacted. Please keep in mind that from now on and throughout the entire experiment you are not permitted to talk to other participants. If you have questions, please give a hand signal and we will come to you. During the experiment you can earn Taler. The amount depends on your decisions and on the decisions of the other participants in your group. At the end of the experiment, the Taler will be converted into EURO by an exchange rate of 1 Taler $=0.06$ Euro. This amount in EURO will be paid to you. Additionally you will receive 4 EURO for showing up and participating in the experiment. You will be called by your cabin number in order to receive your payoff. Please return all the instructions when receiving your money.

Every participant will be randomly assigned to one of two roles: either proposer or responder. In this experiment always two persons (one proposer and one responder) interact.

\section{Description of the game}

At the beginning of the experiment, every proposer receives an initial endowment of 100 Taler. The responder will receive an initial endowment of 60 Taler.

The proposer can transfer an amount of 40 Taler to the responder and therefore ask for a favor. If the proposer decides not to ask for a favor, the game ends and each participant receives his initial endowment, which will be converted into EURO.

If the proposer decides to ask for a favor, the responder can choose one of three possible actions:

1. Rejection of the 40 Taler and not doing a favor

2. Acceptance of the 40 Taler and not doing a favor

3. Acceptance of the 40 Taler and doing a favor

\footnotetext{
${ }^{30}$ These are the instructions for the symmetric treatment, original text was in German and Chinese, respectively. The instruction for asymmetric treatment are the same, except the punishment for the payer was changed to 10 Taler.
} 
If the responder rejects the 40 Taler and does not do a favor, the game ends and each participant receives his initial endowment (converted into EURO).

If the responder accepts the 40 Taler and does not do a favor, the final payoff depends on a decision of the proposer. He can decide if he wants to punish the responder for his refusal to do him a favor or not. If the proposer decides not to punish, the proposer receives his initial endowment minus the transferred 40 Taler (100-40=60 Taler). In this case, the responder will get his initial endowment plus the transferred 40 Taler $(60+40=100)$. If the proposer decides to punish, the responder is fined with 50 Taler and the transferred 40 Taler will be destroyed. The responder receives his initial endowment minus the fine $(60-50=10)$. The punishment will cost the proposer 50 Taler. Thus, he will receive his initial endowment minus the transferred 40 Taler and minus the costs for the punishment $(100-40-50=10)$. Nobody will receive the transferred 40 Taler.

If the responder accepts the 40 Taler and does a favor, the decision about the final payoff depends on a lottery. Then a number between 0 and 99 is randomly drawn. In the unlikely case of the number being 75 or higher, the proposer will suffer a damage of 10 Taler, while the responder will suffer a damage of 50 Taler. The transferred 40 Taler will be destroyed. The proposer will receive his initial endowment minus the transferred 40 Euro and minus the damage $(100-40-50=10$ Taler). The responder will receive his initial endowment minus the damage (60-50=10 Taler). In case of the drawn number being lower than 75 every proposer will get an additional 120 Taler as the result of the favor of the responder. The proposer will receive his initial endowment minus the transferred 40 Taler, plus the additional Taler $(100-40+120=180$ Taler). The responder will receive his initial endowment plus the transferred 40 Taler $(60+40=100)$.

The following graph summarizes the possibilities of decisions and payoffs:

\section{How to make your decision}

At the beginning of the experiment, you will be informed about the role to which you have been assigned (proposer or responder). After this you make your decisions according to your role. Therefore participants who have been assigned to the role of the proposer will decide if they want to transfer 40 Taler and if they want to punish the responder in case he accepts the 40 Taler, but does not do them a favor. The responder will be asked how he would react if the proposer transferred 40 Taler and asked for a favor. He decides if he would reject the offer or if he would accept it without doing the other one a favor or if he would accept it and would do the other one a favor. After all the decisions are made, they will be compared and the actual decisions will be calculated. The payoffs will be calculated as described above. At the end of the experiment, you will be asked to fill out some questionnaires. 


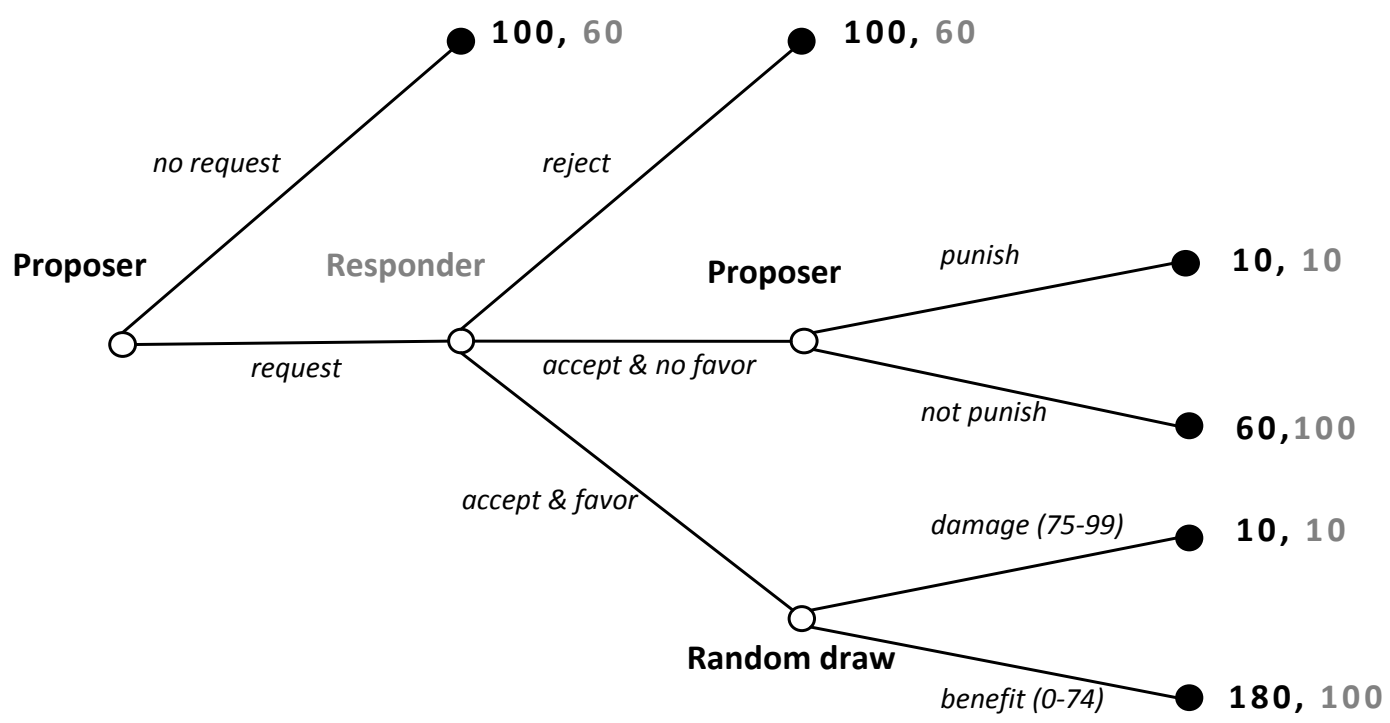

If you have any questions, please raise your hand! 


\section{B Legal Provisions}

\section{Mostly Symmetric Punishment}

- France: French Penal Code, Articles 432-11, 433-1, 433-2, 434-9 provides that both the public official or judge and the briber are "punished by ten years' imprisonment and a fine of 150,000." Ordinance No.2005-759 of 4 July 2005, Official Journal of 7 July 2005, in force 1 July 2006, available via http://195.83.177.9/upl/pdf/code_33. pdf, accessed 24 December 2010.

- Germany: Germany applies symmetric punishment for discharge-of-duty bribery. See German Penal Code (Bohlander, 2008) §331, §333. A public official asking for a bribe for the discharge of an official duty shall be liable to imprisonment of not more than three years or a fine. A judge asking for a bribe having performed, or intending to perform in the future, a judicial act shall be liable to imprisonment of not more than five years or a fine. The person who offers the bribe shall be liable to the same punishment accordingly.

In addition the German system knows asymmetric punishment for violation-of-duty bribery. See German Penal Code (Bohlander, 2008) §332, §334. Under $\S 332$ I StGB, a public official asking for a bribe and thereby having violated or intending to violate his official duties is punished by at least 6 months of imprisonment. Under $\S 334$ I StGB, a payer offering a bribe and causing the official to violate or intending to violate his official duties is punished by at least 3 months of imprisonment. By the same token, under $\S 332$ II StGB, a judge asking for a bribe thereby having violated or intending to violate his judicial duties is punished by at least 1 year of imprisonment. Under $\S 334$ II StGB, a payer offering a judge a bribe and causing the judge to violate or intending to violate his official duties is punished by at least 6 months of imprisonment.

- United Kingdom: The Public Bodies Corrupt Practices Act 1889 s2 and the Prevention of Corruption Act 1906 s1 provides that, both parties of bribery offence "shall be liable: on summary conviction, to imprisonment for a term not exceeding 6 months or to a fine not exceeding the statutory maximum, or to both; and on conviction on indictment, to imprisonment for a term not exceeding 7 years or to a fine, or to both." The 2010 Bribery Act s11 provides that any individual guilty of bribery is liable: on summary conviction, to imprisonment for a term not exceeding 12 months, or to a fine not exceeding the statutory maximum, or to both; on conviction on indictment, to imprisonment for a term not exceeding 10 years, or to a fine, or to both. 
- United Sates: 18 USC $\S 201(b)$ provides that in case of violating the official duty, both the briber and the public official taking a bribe "shall be fined under this title or not more than three times the monetary equivalent of the thing of value, whichever is greater, or imprisoned for not more than fifteen years, or both, and may be disqualified from holding any office of honor, trust, or profit under the United States." §201(c) provides that for discharge of official duty, both the briber and the public official "shall be fined under this title or imprisoned for not more than two years, or both."

At closer sight, the US solution is also not completely symmetric. The 2010 Federal Sentencing Guidelines Manual distinguishes between officials and non-officials when allocating the base level punishment to bribery: it is 14 if the defendant was a public official and 12 otherwise ( $\S 2 \mathrm{C} 1.1$. (a)). Note, however, that in United States v. Booker, 543 U.S. 220 (2005), the Supreme Court decided that the guidelines violate the Sixth Amendment right to trial by jury. Since then, the guidelines have been considered advisory only, at both the federal and the state levels. Sentences above the range of the guidelines are imposed at a rate double that of the rate before Booker. See Doerr (2009).

\section{Mostly Asymmetric Punishment}

- China: The Criminal Law of the People's Republic of China, Article 383, 386, 390, provide, several levels of punishments depending on the seriousness, with the highest punishment being death penalty for the public official and life imprisonment for the briber. Criminal Law of the People's Republic of China, China Legal System Publishing House, 2000, Beijing.

- Japan: Penal Code of Japan, Article 197 through 197-4, 198. For a public official in bribery, "imprisonment with work for not more than 7 years shall be imposed.", and the briber "shall be punished by imprisonment with work for not more than 3 years or a fine of not more than 2,500,000 yen." English translation by the Cabinet Secretariat of Japan, up to the revisions of Act No. 36 of 2006(Effective May 28, 2006), available via http://www.cas.go.jp/jp/seisaku/hourei/data/PC.pdf, accessed on 4 Jan 2011.

- Russia: The Criminal Code of the Russian Federation Article 290 provides "Bribetaking by a functionary, ... if the functionary then takes actions (inaction) which are part and parcel of the functionary's official powers, ... shall be punishable by a fine in the amount of 100 thousand to 500 thousand roubles, or in the amount of the wage 
or salary, or any other income of the convicted person for a period of one to three years, or by deprivation of liberty for a term of up to five years, with deprivation to hold specified offices or to engage in specified activities for a term of up to three years. Bribe-taking by a functionary for illegal actions (inaction) shall be punishable by deprivation of liberty for a term of three to seven years, with disqualification to hold specified offices or to engage in specified activities for a term of up to three years." Article 291 provides "Bribe- giving to a functionary, in person or through a mediator, shall be punishable by a fine in the amount up to 200 thousand roubles, or in the amount of the wage or salary, or any other income of the convicted person for a period up to 18 months, or by corrective labor for a term of one to six months, or by arrest for a term of three up to six months, or by deprivation of liberty for a term of up to three years; bribe-giving to a functionary for the commission of known illegal actions (inactions) shall be punishable by a fine in the amount of 100 thousand to 500 thousand roubles, or in the amount of the wage or salary, or any other income of the convicted person for a period of one to three years, or by deprivation of liberty for a term of up to eight years." NO. 63-FZ OF JUNE 13, 1996 (with the last amendment on December 28, 2004). Adopted by the State Duma on May 24, 1996, adopted by the Federation Council on June 5, 1996, available via http://www.legislationline. org/documents/section/criminal-codes, accessed on 4 Jan 2011. 


\section{Screenshots}

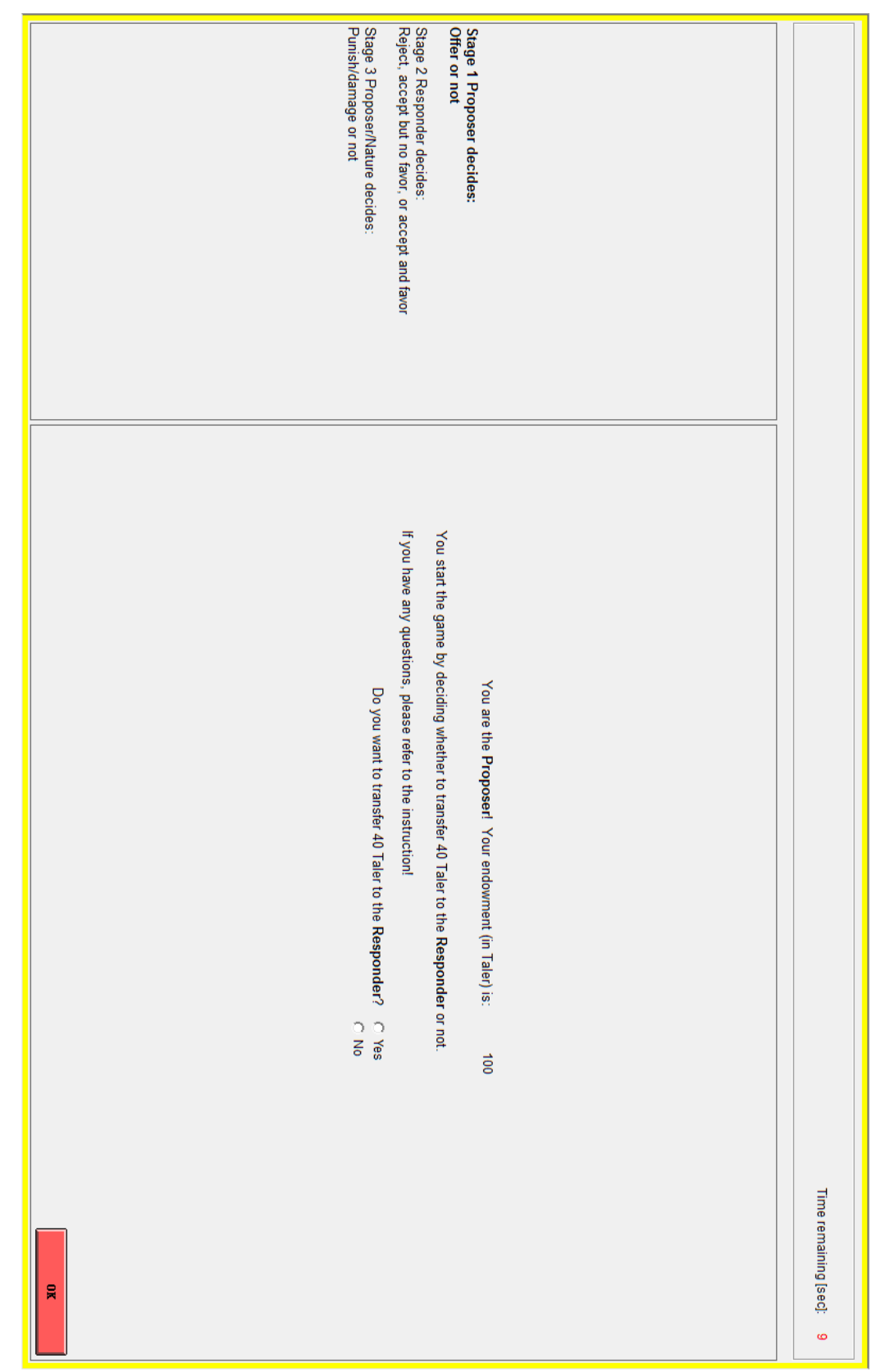




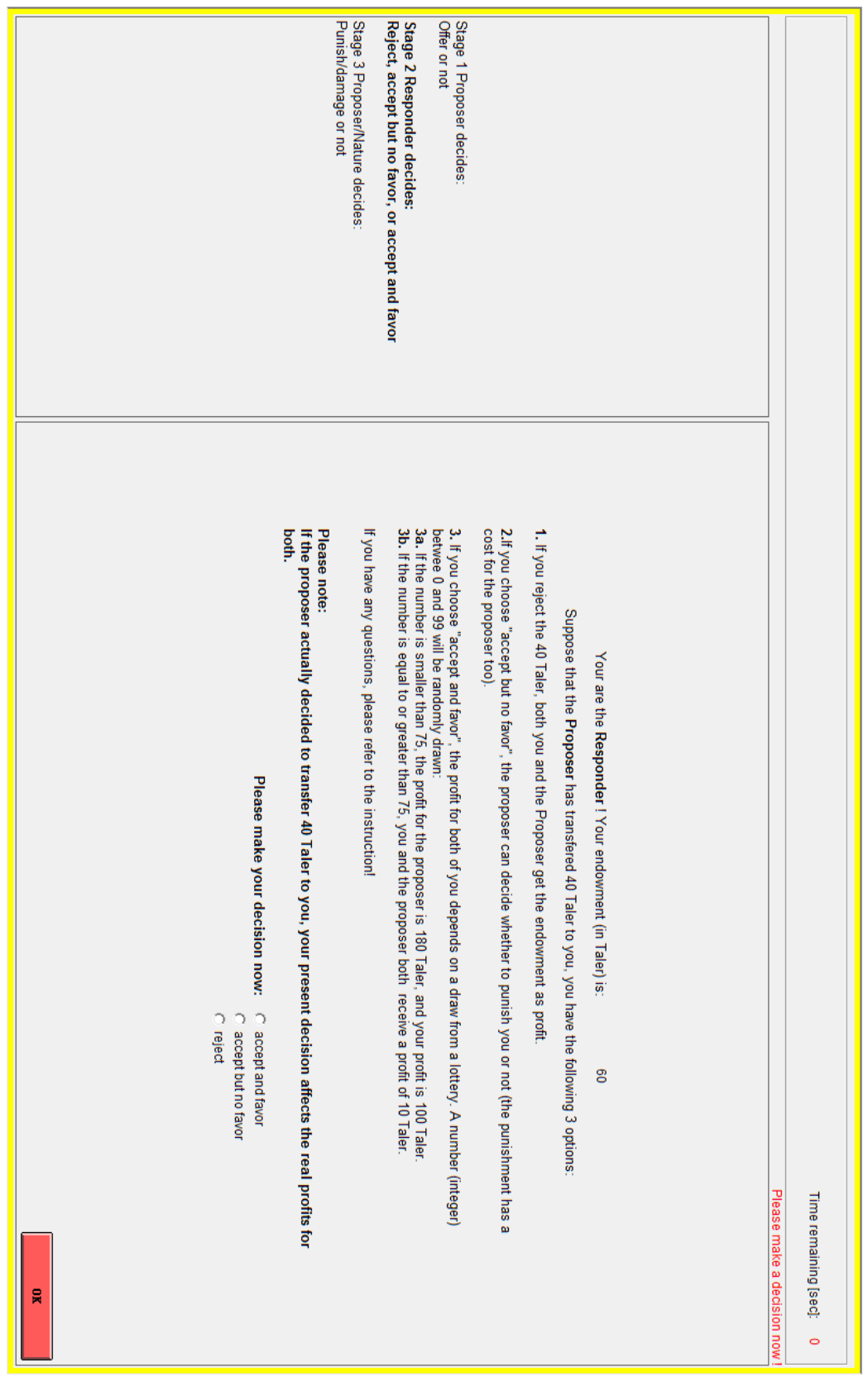




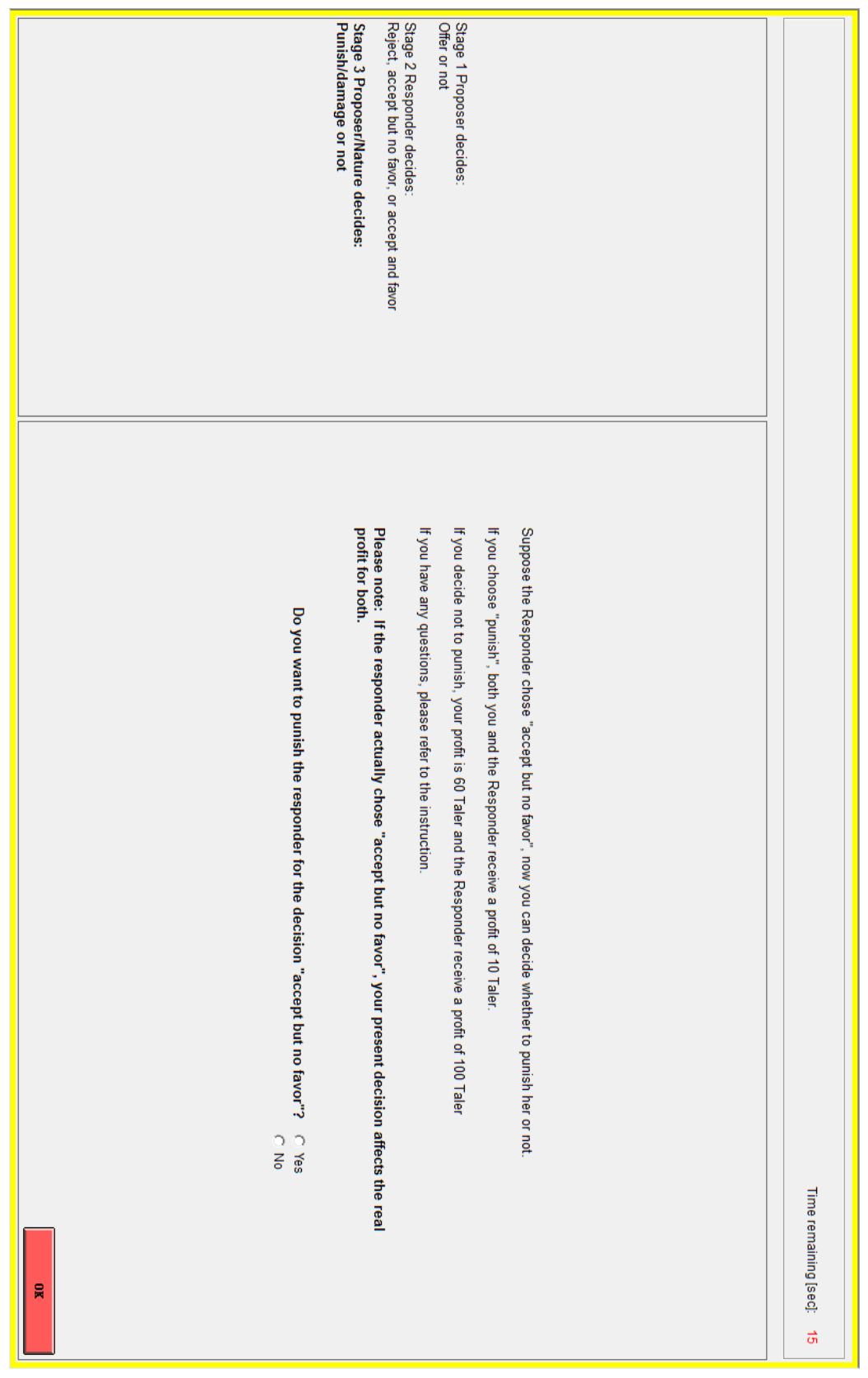

